\title{
Synaptic Plasticity in Drosophila Memory and Hyperexcitable Mutants: Role of CAMP Cascade
}

\author{
Yi Zhong, Vivian Budnik, ${ }^{a}$ and Chun-Fang Wu \\ Department of Biology, University of lowa, lowa City, lowa 52242
}

\begin{abstract}
Activity-dependent synaptic plasticity has been implicated in the refinement and modification of neural circuits during development and learning. Previous studies show that activity-induced facilitation and potentiation are disrupted at larval neuromuscular junctions in the memory mutants dunce (dnc) and rutabaga (rut) of Drosophila. The diminished learning-memory capacity and synaptic transmission plasticity have been associated with altered cAMP levels since dnc affects the CAMP-specific phosphodiesterase and rut affects adenylate cyclase. In this study, the morphology of larval motor axon terminals was examined by anti-HRP immunohistochemistry. It was found that the numbers of terminal varicosities and branches were increased in dnc mutants, which have elevated CAMP concentrations. Such increase was suppressed in dnc rut double mutants by rut mutations, which reduce CAMP synthesis. More profuse projections of larval motor axons have also been reported in double-mutant combinations of ether à go-go (eag) and Shaker (Sh) alleles, which display greatly enhanced nerve activity as a result of reduction in different $\mathrm{K}^{+}$currents. Therefore, we examined combinations of dnc and rut with eag and Sh mutations to explore the possible relation between activity- and CAMPinduced morphological changes. We found that the expanded projections in dnc were further enhanced in double mutants of dnc with either eag or Sh, an effect that could again be suppressed by rut. The results provide evidence for altered plasticity of synaptic morphology in memory mutants dnc and rut and suggest a role of CAMP cascade in mediating activity-dependent synaptic plasticity.
\end{abstract}

Increasing evidence has suggested that electric activity-controlled mechanisms may play a crucial role in the "fine tuning" of functional architecture of neural circuits (Harris, 1981; Udin and Fawcett, 1988; Lnenicka and Murphey, 1989; ConstantinePaton et al., 1990). One such classical example is the role of the visual experience in shaping synaptic patterns of the visual cortex (Hubel et al., 1977). More direct evidence has been revealed by application of TTX to block the $\mathrm{Na}^{+}$channel-dependent action potential (Brown and Ironton, 1977; Harris, 1981; Meyer, 1982; Schmidt and Edwards, 1983; Reh and Constantine-Paton, 1985). TTX blockade of retinal ganglion cells prevents the for-

\footnotetext{
Received June 21, 1991; revised Sept. 16, 1991; accepted Sept. 25, 1991.

We thank Drs. M. Gorczyca, M. Saito, and E. Cole for comments on the manuscript and Drs. M. Feany and J. Kiger for providing mutant stocks.

Correspondence should be addressed to Chun-Fang Wu at the above address.

a Present address: Department of Zoology, Morrill Science Center, University of Massachusetts, Amherst, MA 01003.

Copyright (c) 1992 Society for Neuroscience $0270-6474 / 92 / 120644-08 \$ 05.00 / 0$
}

mation of ocular dominance stripes that delineate the projections from the normal and ectopic eyes in the frog tectum (Reh and Constantine-Paton, 1985). TTX blockade also induces motor nerve terminal sprouting in vertebrate neuromuscular junctions (Brown and Ironton, 1977).

In invertebrates, electric activity has also been shown to be involved in the regulation of neural circuits during development (Lnenicka and Murphey, 1989; Atwood and Govind, 1990). Chronic stimulation of relatively silent phasic motoneurons in the crayfish induces changes in the number and shape of synapses formed at the motor terminals (Lnenicka et al., 1986). Hyperexcitability induced by genetic lesions of $\mathrm{K}^{+}$channels also correlates to expanded terminal projection in Drosophila motor axons (Budnik et al., 1990). In addition, direct electric stimulation on cultured neurons has been reported to influence growth cone motility and neurite elongation (Kater et al., 1988; Kater and Mills, 1991).

The molecular basis of this electric activity-controlled mechanism remains to be established. The activation of the NMDA subclass of excitatory glutamate receptors has been suggested to mediate the activity-dependent plasticity in the visual cortex and in the retinotectal projection (Constantine-Paton et al., 1990; Cline, 1991), but there is no unambiguous information on the biochemical events subsequent to NMDA receptor activation. Even less is known in other preparations. Studies of cultured neurons have provided suggestive clues. For instance, changes in intracellular $\mathrm{Ca}^{2+}$ or cAMP concentrations have been shown to be critical for regulating the growth cone motility and neurite elongation (Forscher et al., 1987; Kater et al., 1988; Kater and Mills, 1991). It appears that second messenger cascades may be important factors in shaping nerve terminal arborization.

We examined Drosophila mutants with altered cAMP cascade to investigate whether the cAMP cascade is involved in modifying the nerve terminal arborization and how the pathway is related to activity-dependent synaptic plasticity. The dunce $(d n c)$ and rutabaga (rut) mutants, initially isolated as learning and memory mutants, have been shown to be defective in the cAMP metabolic pathway (Tully, 1984; Dudai, 1988). The $d n c$ gene encodes phosphodiesterase II, an enzyme for cAMP hydrolysis (Byers et al., 1981; Chen et al., 1986). The reduction $\left(d n c^{2}\right)$ or elimination ( $d n c^{M 11}$ and $d n c^{M 14}$ ) of phosphodiesterase II activity cause elevated cAMP in the $d n c$ alleles (Byers et al., 1981). In contrast, the rut locus appears to code for a subunit of adenylate cyclase (Livingstone et al., 1984; Krupinski et al., 1989). The rut $^{\prime}$ mutation eliminates $\mathrm{Ca}^{2+}$ /calmodulin $\left(\mathrm{Ca}^{2+} / \mathrm{CaM}\right)$ activation of adenylate cyclase and reduces its basal activity (Dudai and $\mathrm{Zvi}, 1984$; Livingstone et al., 1984), leading to reduced cAMP concentration. A weaker allele, $r u t^{2}$, only reduces the 
basal activity of adenylate cyclase, but does not abolish its activation by $\mathrm{Ca}^{2+} / \mathrm{CaM}$ (Feany, 1990).

We report that $d n c$ mutants showed an enhanced motor terminal arborization, suggesting that cAMP levels influence the size of motor axon projections. This was further supported by the result that the effect of $d n c$ mutations on nerve terminal arborization could be counterbalanced by $r u t^{I}$ as reflected in $d n c$ rut ${ }^{1}$ double mutants.

It has been reported that hyperexcitability observed in double mutants with defects in different $\mathrm{K}^{+}$channels or with abnormal expression of $\mathrm{Na}^{+}$channels can be correlated with expansion of terminal projections (Budnik et al., 1990). For example, enhanced arborization can be seen in double-mutant combinations of ether à go-go (eag) and Shaker (Sh), each affecting different $\mathrm{K}^{+}$channels (Jan et al., 1977; Wu et al., 1983; Ganetzky and Wu, 1986; Salkoff and Tanouye, 1986; Zhong and Wu, 1991b). Such effect is not present in eag or Sh single mutants and can be suppressed in eag $S h$; nap (no action potential) triple mutants (Budnik et al., 1990) by nap, a mutation causing reduction in $\mathrm{Na}^{+}$channel density (Wu et al., 1978; Jackson et al., 1984; Ganetzky and $\mathrm{Wu}, 1986)$. We examined the combinations of $d n c$ and rut with hyperexcitability mutations and found that $d n c$ mutations potentiated the effects of either $S h$ or eag single mutants. The enhancement could again be counterbalanced by the presence of $r u t^{1}$ in $d n c$ rut $S h$ triple mutants. However, the effect of the extreme hyperexcitability in eag $S h$ was not further promoted in $d n c$ eag $S h$. Our results indicated that the cAMP cascade may be crucial to regulation of nerve terminal arborization, and support the view that synaptic plasticity may be mediated by activity-dependent accumulation of intracellular $\mathrm{Ca}^{2+}$ that in turn triggers sccond messenger cascades.

\section{Materials and Methods}

\section{Fly stocks}

Drosophila melanogaster stocks were reared at room temperature (20$23^{\circ} \mathrm{C}$ ). The Canton-Special strain was used as normal control fies. The molecular lesions and physiological characteristics of the mutants used are summarized below.

$S h^{\text {KOI20 }}$. The Shaker locus (mapped to 1-57.4) encodes $\mathrm{K}^{+}$-channel subunits. This $S h$ allele displays reduced A-type $\mathrm{K}^{+}$current $\left(I_{\mathrm{A}}\right)$ in larval muscles and enhances nerve excitability and synaptic transmission at larval neuromuscular junctions (Ganetzky and Wu, 1983; Haugland and $\mathrm{Wu}, 1990$ ).

$S h^{133}$. The mutation eliminates $I_{\mathrm{A}}$ in larval muscles and enhancing transmission at larval neuromuscular junctions (Jan et al., 1977; Ganetzky and $\mathrm{Wu}, 1983$; Haugland and $\mathrm{Wu}, 1990$ ).

eag. . The ether à go-go locus $(1-48.9)$ encodes a $\mathrm{K}^{+}$-channel polypeptide (Warmke et al., 1991). The mutation reduces several $\mathrm{K}^{+}$currents in larval muscles and interacts synergistically with $S h$ mutations to enhance nerve excitability and neuromuscular transmission (Ganetzky and $\mathrm{Wu}, 1983$; Wu et al., 1983; Zhong and Wu, 199lb).

$d n c^{l}$. This allele of dunce $(1-4.6)$ was isolated as a learning mutant (Dudai et al., 1976). The mutation reduces the phosphodiesterase II activity, leading to a higher concentration of cAMP (Byers et al., 1981).

$d n c^{M / 4}$. This extreme allele was isolated because of female sterility (Mohler, 1977). It also eliminates phosphodiesterase II activity and shows learning deficiency (Byers et al., 1981).

$d n c^{M I I}$. The phenotype of this mutant is similar to $d n c^{M I I}$ (Mohler, 1977; Byers et al., 1981). In addition, protein kinase C activity is reported to be altered in this stock by a separate mutation at a closely linked locus yet to be identified (Devay et al., 1989).

rut $^{I}$. This allele of rutabaga $(1-46)$ was isolated by deficiency in an associative learning paradigm (Aceves-Pina et al., 1983). The mutation eliminates $\mathrm{Ca}^{2+} / \mathrm{CaM}$ activation of adenylate cyclase and reduces its basal activity (Dudai and Zvi, 1984; Livingstone et al., 1984).

$r u t^{2}$. This allele was isolated by its partial suppression of female sterility in $d n c^{M 11}$ and $d n c^{M 14}$ (Bellen et al., 1987). The basal activity of adenylate cyclase is reduced but its activation by $\mathrm{Ca}^{2+} / \mathrm{CaM}$ is.preserved (Feany, 1990).

The double- and triple-mutant strains used were derived from recombinations among those described above. The presence of eag, $S h$, $d n c$, and rut mutations in the recombinants was confirmed by testing the leg-shaking behavior (Ganetzky and $\mathrm{Wu}, 1986)$, wing position (Ganetzky and Wu, 1983; Drysdale et al., 1991), dnc-associated female sterility (Mohler, 1977), and rescue of this sterility by rut (Livingstone et al., 1984; Bellen et al., 1987), as well as flanking morphological markers. The morphological markers used included $y, c v, v, g$, sd, and $f$, which have been described in Lindsley and Grell (1968).

\section{Immunohistochemistry}

The larval neuromuscular preparation and the anti-HRP staining protocol have been described previously (Johansen et al., 1989a; Budnik et al., 1990). Briefly, late third instar larvae were dissected in saline and then fixed in nonalcoholic Bouin's solution $(25 \mathrm{ml}$ formalin, $5 \mathrm{ml}$ glacial acetic acid, $75 \mathrm{ml}$ saturated picric acid) for 1-2 hr. The samples were then incubated sequentially with 1:200 anti-HRP (Sigma) and 1:20 HRPconjugated goat anti-rabbit IgG (Cappel). Staining was revealed by HRPcatalyzed diaminobenzidine reaction.

\section{Results}

Increased terminal branching and varicosities in dnc mutants The segmental body-wall muscle fibers in Drosophila larvae are organized in a regular pattern (Crossley, 1978; Johansen et al., 1989a). Within individual identifiable fibers, motor axon terminals exhibit distinct branching patterns (Johansen et al., 1989a,b; Budnik et al., 1990). Our studies focused on muscle fibers 12 and 13 in abdominal segment 3 of third instar larvae (Johansen et al., 1989a; Budnik et al., 1990). The motor terminals at these two muscle fibers have been extensively studied with anti-HRP immunohistochemical staining (Budnik et al., 1990), which specifically labels insect neurons (Jan and Jan, 1982). Nerve processes on these two muscle fibers project both anteriorly and posteriorly with varicosities distributed along their branches (Fig. 1; see also Johansen et al., 1989a; Budnik et al., 1990). Such varicosities are thought to be synaptic sites (Bailey and Chen, 1983; Johansen et al., 1989a; Budnik et al., 1990).

Using the same immunohistochemical technique, we compared the numbers of varicosities and branches in normal and $d n c$ larvae. It is important to examine multiple $d n c$ alleles and their heterozygous combinations such that any abnormal morphology observed could be attributed to the $d n c$ locus. In three independently isolated alleles, $d n c^{I}, d n c^{M I I}$, and $d n c^{M 14}$, phosphodiesterase II activity is reduced in $d n c^{i}$ and eliminated in the other two, leading to elevated cAMP and learning deficits (Byers et al., 1981; Tully, 1984; Dudai, 1988). The number of terminal varicosities was found to be increased in $d n c^{l}$ and $d n c^{M 14}$ mutants (Figs. 1, 2). Furthermore, $d n c^{l} / d n c^{M 11}$ (Fig. 2) heterozygote showed similar increase in the number of varicosities. However, such a change was not observed in $d n c^{M 11}$ larvae $\left[d n c^{M 11}\right.$ (mean \pm SD): $234 \pm 29,6$ larvae; normal: 238 \pm 39, 23 larvae; see Materials and Methods and Discussion for the possibility of a separate mutation on the $d n c^{M l l}$ chromosome].

The increase in varicosity number was associated with more extensive branching, as suggested by the representative tracings in Figure 1. A branch is defined as a terminal process containing at least two varicosities. The total number of all terminal branches in both muscles 12 and 13 in normal and $d n c$ larvae is summarized in Figure 2, which indicates statistically significant increases in $d n c^{l}, d n c^{M / 4}$, and $d n c^{l} / d n c^{M 11}$ larvae. To illustrate the extent and variability of branching in different genotypes, we 


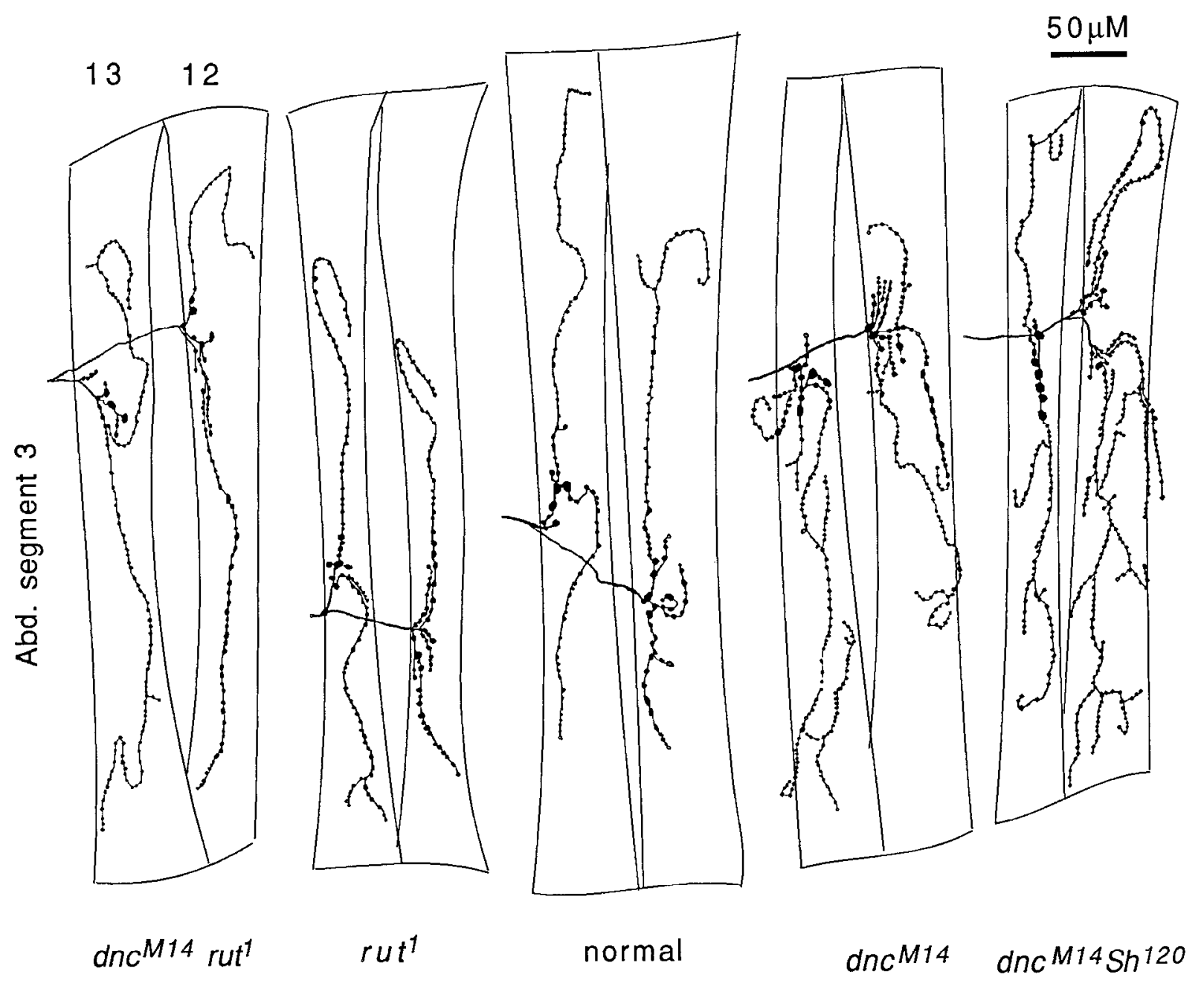

Figure 1. Camera lucida tracings of anti-HRP staining of motor axon terminals on muscle fibers 12 and 13 of abdominal segment 3 in third instar larvae of Drosophila. Data for normal and rut were from a right hemisegment (posterior on top), and those from $d n c^{M / 4} r u t^{l}, d n c^{M 14}$, and $d n c^{M / 4} S h^{120}$ were from a left hemisegment (anterior on top). The fine neurites in the tracings presented here are thickened for clarity, partially masking some smaller varicosities. Individual varicosities were more clearly resolved in photomicrographs (see, e.g., Budnik et al., 1990).

compiled isomorphic representations (Fig. 3), each depicting the branching pattern of a single primary process that showed the highest number of branches in either muscle fiber 12 or 13 individual larvae. Branching appears to be more extensive in the $d n c$ alleles as indicated by more higher-order branches (Fig. $3)$.

\section{Suppression of dnc-induced enhancement by rut mutations}

If the increase in branching and number of varicosities in $d n c$ alleles is attributable to elevated cAMP, the alterations may be counterbalanced by the rut mutations. The rut gene is thought to encode a subunit of adenylate cyclase for cAMP synthesis (Livingstone et al., 1984; Krupinski et al., 1989; Feany, 1990). The basal cAMP synthesis is lowered in both $r^{\prime} t^{l}$ and $r u t^{2}$ (Dudai and Zvi, 1984; Livingstone et al., 1984; Feany, 1990). However, the $\mathrm{Ca}^{2+} / \mathrm{CaM}$-dependent activation of adenylate cyclase is eliminated in rut ${ }^{1}$ flies (Dudai and Zvi, 1984; Livingstone et al., 1984) but retained in the weaker allele $r u t^{2}$ (Feany, 1990). We examined rut larvae as well as $d n c$ rut double mutants.

The number of branches and varicosities in rut ${ }^{l}$ showed a slight, but statistically insignificant ( $t$ test, $p>0.05$ ), decrease as compared to normal larvae (Fig. 2). However, the effects of $d n c^{M 14}$ on terminal morphology were suppressed in the double mutant $d n c^{M 14}$ rut $^{l}$ (Figs. 1-3). Interestingly, the numbers of varicosities and branches in $d n c^{M 14} r u t^{2}$ remained similar to that in $d n c^{M 14}$ (Fig. 2), but terminal morphology returned to normal in the mutant $d n c^{d 11^{4}} r u t^{1} / d n c^{M 14} r u t^{2}$ (Fig. 2). This result is in agreement with biochemical measurements that indicate that cAMP synthesis in $r u t^{2} / r u t^{1}$ heterozygotes is lower than that in $r u t^{2}$ homozygotes (Feany, 1990).

\section{Synergistic effects of dnc with hyperexcitability mutations}

Double mutants of different eag and $S h$ alleles show greatly enhanced neuronal excitability (Ganetzky and Wu, 1983) and display morphological changes in motor terminals (Budnik et al., 1990) similar to those in $d n c$ alleles (Figs. 4, 5). Action potential duration is increased in $S h$ mutants as shown in the cervical giant nerve fibers (Tanouye and Ferrus, 1985), and neuromuscular transmission is also enchanced in both eag and Sh larvae (Jan et al., 1977; Ganetzky and Wu, 1983). Electrophysiological recordings from eag $S h$ double mutants have demonstrated a synergistic interaction between the two mutations, leading to abnormal spontaneous firing (Ganetzky and $\mathrm{Wu}, 1983$; Budnik et al., 1990) and greatly enhanced transmitter release 


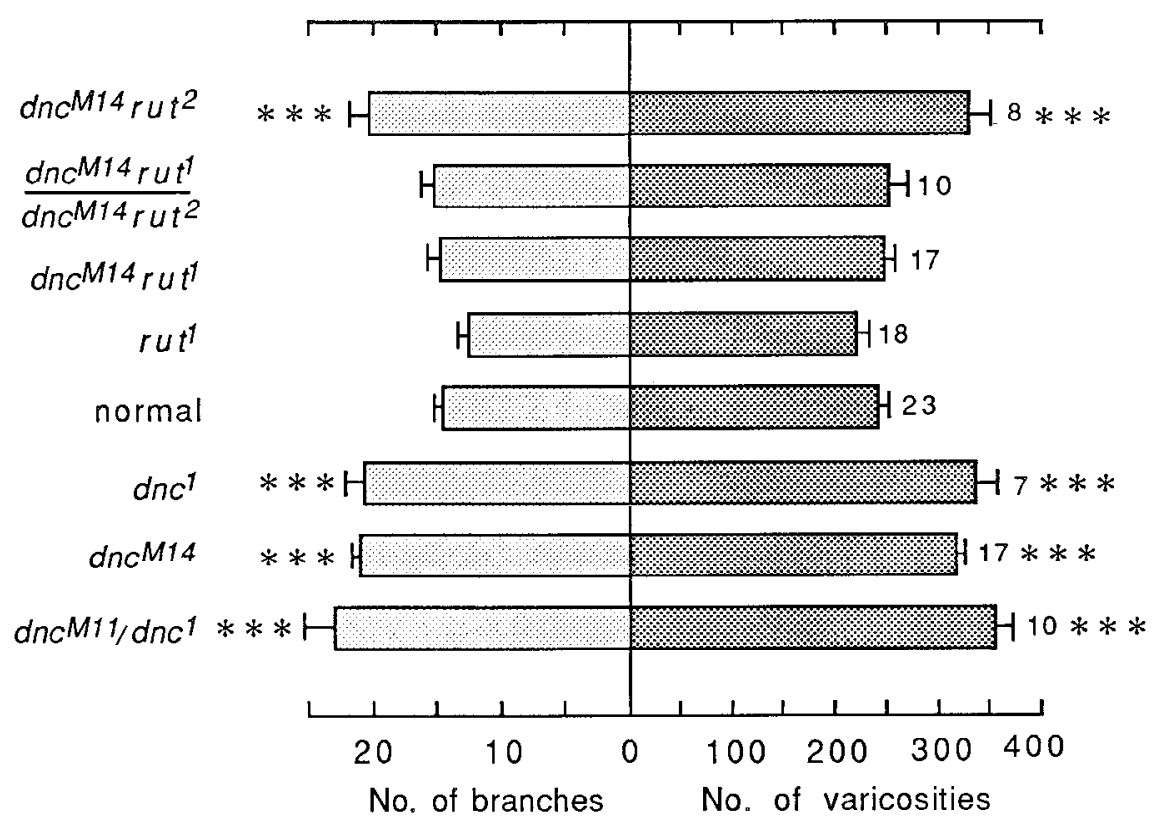

Figure 2. Increase in number of branches and varicosities in $d n c$ alleles and suppression of $d n c$ phenotype by rut: the total numbers of varicosities and branches on both muscle fibers 12 and 13 in one hemisegment. A branch is defined as a terminal process containing at least two varicosities. The mean and SEM in each genotype are presented for the number of larvae indicated. For each batch of samples, we used muscles 12 and 13 in each larva from the same side of segment 3 , and only if this was prevented by damage or unsatisfactory staining was the other side used. Mutant data are compared to normal with $t$ test, and statistically significant differences are indicated $(*$, $\left.p<0.05{ }^{* *}, p<0.01{ }^{* * *}, p<0.001\right)$.
(Ganetzky and $\mathrm{Wu}, 1983$ ) at larval neuromuscular junctions. Combinations of $d n c$ and eag or $S h$ provide a means to study the possible mechanistic connection between $d n c$ - and eag $S h$ induced morphological changes.

Neither eag nor $S h$ alone affected the morphology of axon terminals significantly (Figs. 4, 5; also see Budnik et al., 1990). However, both mutations were found to interact with the $d n c$ mutation to enhance the $d n c$ phenotypes. Compared to $d n c^{M 14}$ (Fig. 4), the number of varicosities was increased in double mutants $d n c^{M 14} S h^{120}(t$ test, $p<0.02)$ and $d n c^{M 14} e a g^{I}(p<0.05)$ and the number of branches was increased in $d n c^{M 14} S h^{120}(p<$ $0.02)$ and $d n c^{114} S h^{133}(p<0.05)$. The enhancement by eag or $S h$ was more evident in the extent of higher-order branching as indicated by the isomorphic representations (Fig. 5). The above double-mutant phenotypes could again be suppressed by rut ${ }^{1}$ as shown in the triple mutant $d n c^{M 14} \mathrm{rut}^{1} \mathrm{Sh}^{120}$ (Figs. 4, 5).

Surprisingly, we observed no further increase ( $t$ test, $p>0.05$ ) in the number of varicosities or branches in the triple mutant $d n c^{M 14} e^{2 a g^{1}} S h^{120}$ and $d n c^{M 14} e^{2} g^{1} S h^{133}$ compared to $d n c^{M 14}$ or eag Sh mutants (Fig. 4). Moreover, there was a statistically significant decrease in the number of branches compared to $d n c^{M 14} S h$ $(p<0.02)$ or $d n c^{M 14} e a g^{I}(p<0.05)$ (see Discussion).

\section{Discussion}

\section{cAMP-induced nerve terminal expansion}

It has been shown that injecting cAMP into Aplysia sensory neurons increases the number of varicosities (Nazif et al., 1991). In addition, application of cAMP can influence growth cone motility (Forscher et al., 1987), neurite elongation (Rydel and Greene, 1988), and synaptogenesis (Dubinsky and Fischbach, 1990 ) in cultured neurons. The present study revealed increased terminal branching and synaptic contacts in multiple $d n c$ alleles; these defects could be rescued by mutations at a second locus, rut. Since $d n c$ and rut mutations disrupt different steps in the cAMP metabolism pathway (Byers et al., 1981; Dudai and Zvi, 1984; Livingstone et al., 1984; Tully, 1984; Dudai, 1988), our results provide in vivo genetic evidence that alterations in CAMP concentration affect motor terminal morphology.
Although expanded nerve terminal projection was not observed in homozygous $d n c^{M I}$ larvae, the phenotype of $d n c^{I /}$ $d n c^{M 11}$ heterozygotes (Figs. 2, 3) supports the idea that the $d n c^{M I}$ chromosome used may carry some unidentified recessive mutations (Devay et al., 1989; see also Materials and Methods) that masked the $d n c$ effect on terminal arbors. This recessive trait apparently manifests only in homozygous form but is not expressed in heterozygotes carrying two different $d n c$ chromosomes.

The cAMP-induced nerve terminal expansion is most evident in high-order branches, which contain small-sized varicosities

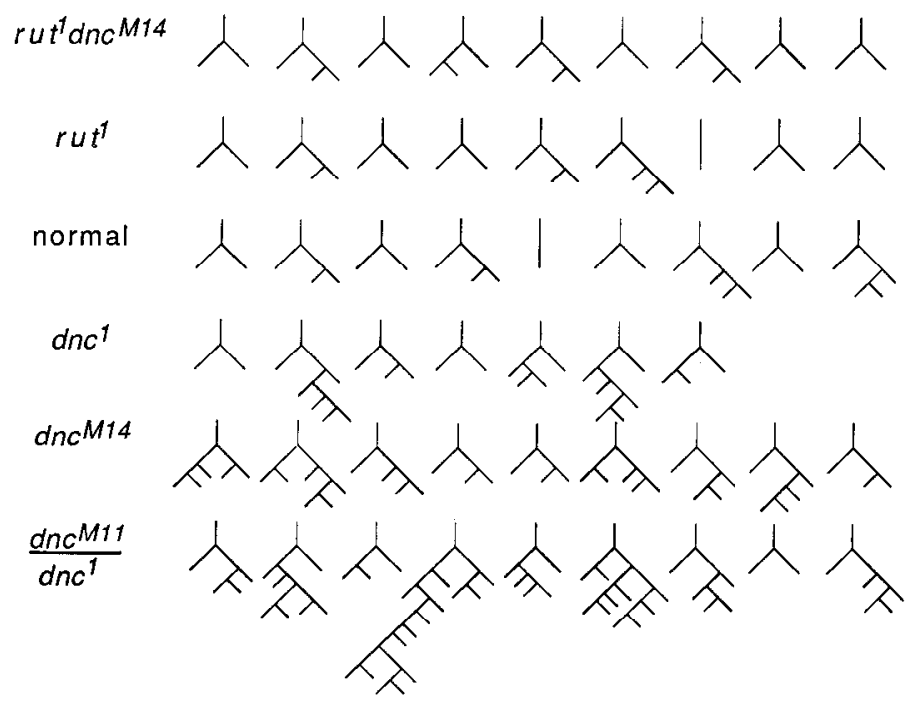

Figure 3. Isomorphic representations of branching pattern. Each representation illustrates the branching pattern of the single primary process that showed the highest number of branching in either muscle fiber 12 or 13. More extensive branching is seen in $d n c$ alleles while the enhanced branching is suppressed by additional rut mutations in dnc rut double mutants. If the sample number is higher than nine in a genotype, only the first nine larvae during sampling are presented. 
eag $^{1} \mathrm{Sh}^{133}$

eag 1 Sh 120

Figure 4. Changes in morphology of motor terminals induced by altered nerve excitability and cAMP levels. Data collection and analysis were the same as in Figure 2. Branches and varicosities were increased in eag $S h$ double mutants but not in either eag or $S h$ mutants (eag, $S h$, and eag $S h$ data based on results shown in Budnik et al., 1990, plus new samples). However, eag and $S h$ significantly enhanced the $d n c$ phenotype in $d n c$ eag and $d n c S h$ double mutants (see Results). This enhancement was suppressed by rut in the dnc rut $S h$ triple mutant.
$\operatorname{Sh}^{133}$

$\operatorname{Sh}^{120}$

$\operatorname{eag}^{1}$

normal

dnc $M 14$

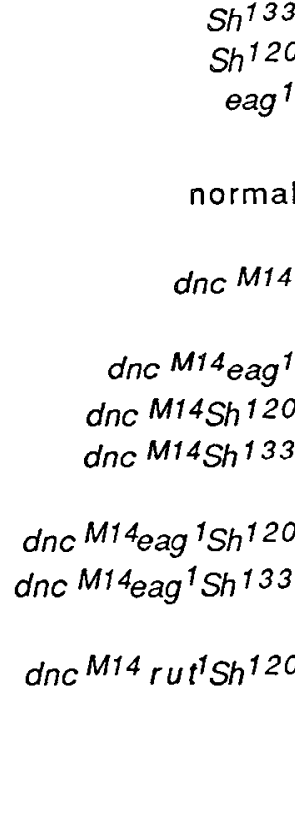

(1)
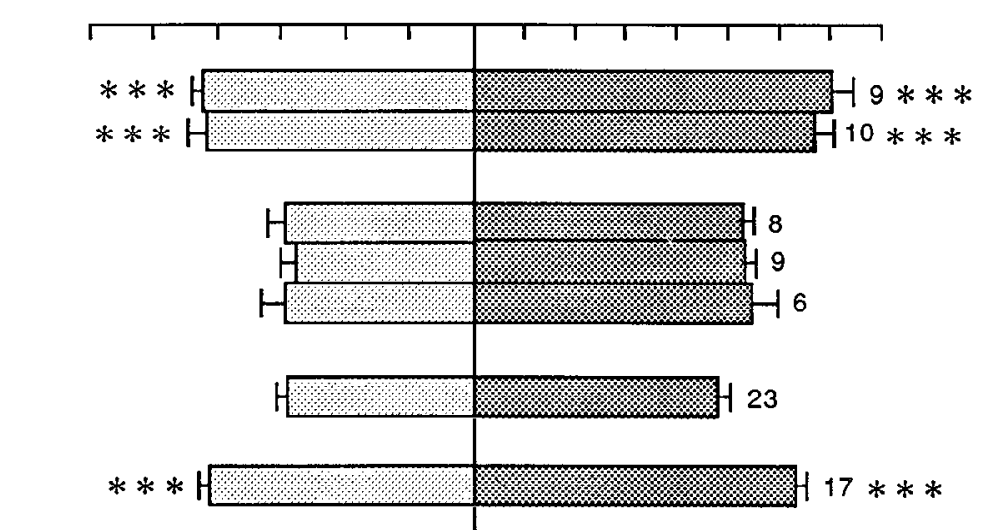


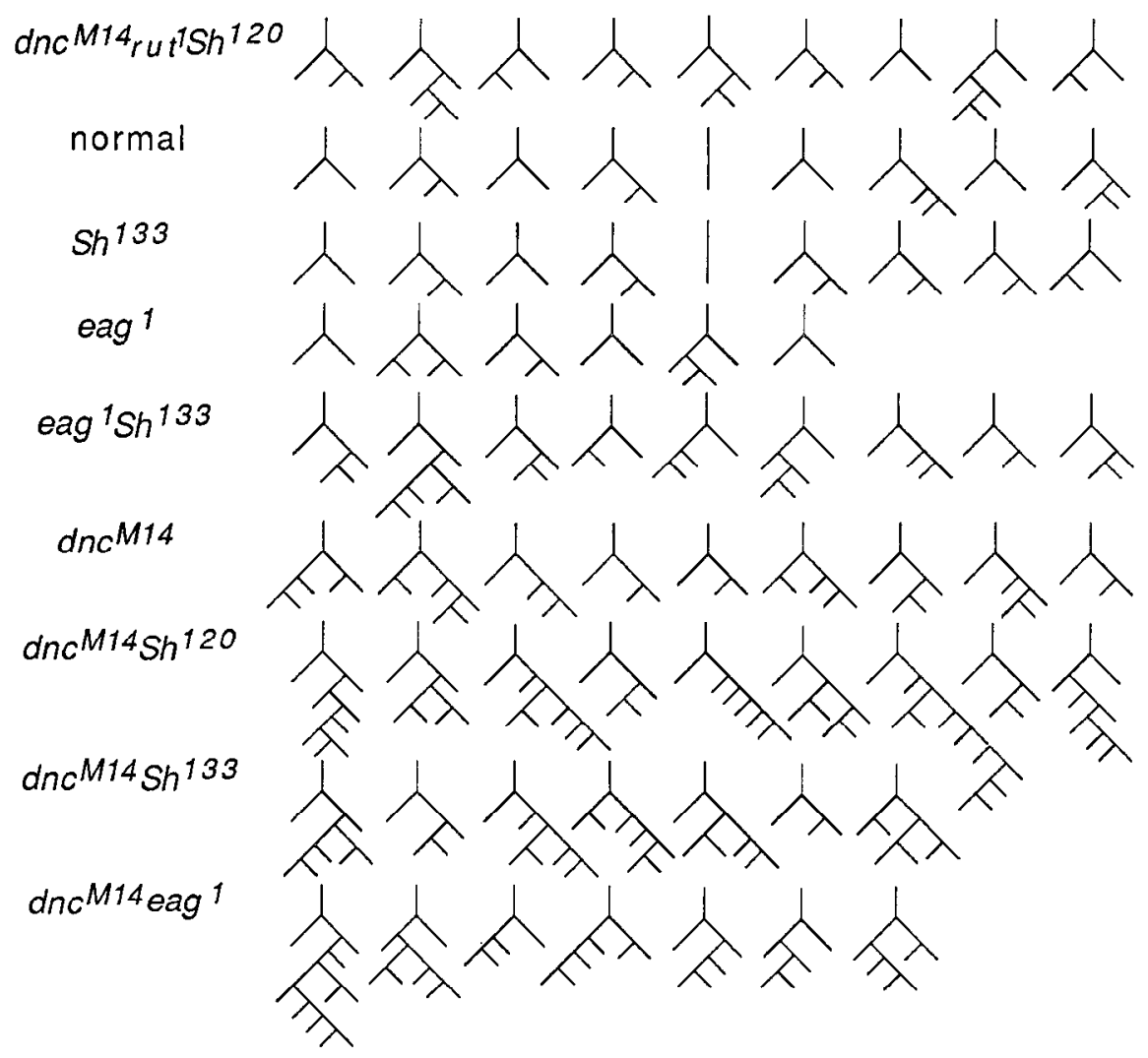

Figure 5. Isomorphic representations of branching patterns in different genotypes. Interactions between $S h$ or $e a g$ with $d n c$ mutations induce further ramification in nerve terminal branching. duced in dnc eag Sh as compared to dnc eag or $d n c$ Sh (Fig. 4). One possibility is that if cAMP is higher than an optimal level, presumably in the case of the triple mutants dnc eag $S h$, terminal growth may not be further promoted. This is not surprising since the operation of some steps in second messenger systems requires optimal stimuli. For example, $\mathrm{Ca}^{2+}$ activation of adenylate cyclase occurs only in a narrow concentration range (Livingstone et al., 1984; Feany, 1990). Other complications, such as compartmentalization of the subtypes of cAMP-dependent protein kinases with different substrates, may also induce nonlinear cellular responses (Nairn et al., 1985; Adam and Friedrich, 1988).

Alternatively, increased intracellular $\mathrm{Ca}^{2+}$ concentrations may also activate $\mathrm{Ca}^{2+} / \mathrm{CaM}$-dependent or $\mathrm{Ca}^{2+}$ /phospholipid-dependent protein kinases (Nairn et al., 1985), in addition to stimulating c $\Lambda \mathrm{MP}$ synthesis. These protein kinases may have different substrates or may share the same targets with cAMPdependent protein kinase but exerting differential cellular effects (Nairn et al., 1985). Different sensitivity of these cascades to $\mathrm{Ca}^{2+}$ concentration may further complicate the situation. Studies of cultured snail neurons show that axonal outgrowth is promoted only in an optimal range of intracellular $\mathrm{Ca}^{2+}$ concentration; concentrations outside this range result in decreased outgrowth (Kater and Mills, 1991).

\section{Altered synaptic plasticity in terminal arborization of memory mutants}

In the rat and Aplysia, nerve terminal projections and synaptic connectivity are thought to be modified in association with learning processes (Bailey and Chen, 1983; Greenough and Bailey, 1988). The fine tuning of morphological structures may be defective across the nervous system in Drosophila memory mutants. It has been reported that the number of nerve fibers in the mushroom body (Balling et al., 1987) and the varicosity number in a branch of an identified sensory neuron (Corfas and Dudai, 1991) are altered in certain $d n c$ and rut alleles. In addition, reduction in growth cone motility has been indicated in cultured neurons from the dnc and rut larval CNS (Y.-T. Kim and C.-F. Wu, unpublished observations). We have shown that $d n c$ may further potentiate activity-dependent modification of nerve terminal morphology (Fig. 4). It will be important to determine how this defective regulation in morphological plasticity acts together with altered facilitation and potentiation in synaptic transmission reported in these mutants (Zhong and $\mathrm{Wu}, 199 \mathrm{la}$ ) to cause learning and memory deficiency.

\section{References}

Aceves-Pina EO, Booker R, Duerr JS, Livingstone MS, Quinn WG, Smith RF, Sziber PP, Tempel BL, Tully TP (1983) Learning and memory in Drosophila, studies with mutants. Cold Spring Harbor Symp Quant Biol 48:831-840.

Adam $G$, Friedrich P (1988) Microtubule-associated cyclic AMPdependent protein kinase in Drosophila melanogaster. J Neurochem 51:1014-1022.

Atwood HL, Govind CK (1990) Activity-dependent and age-dependent recruitment and regulation of synapses in identified crustacean neurons. J Exp Biol 153:105-127.

Bailey $\mathrm{CH}$, Chen $\mathrm{M}$ (1983) Morphological basis of long-term habituation and sensitization in Aplysia. Science 220:91-93.

Balling A, Technau GM, Heisenberg M (1987) Are the structural changes in adult Drosophila mushroom bodies memory traces? Studies on biochemical learning mutants. J Neurogenet 4:65-73.

Bellen HJ, Gregory BK, Olsson CL, Kiger JA (1987) Two Drosophila learning mutants, dunce and rutabaga, provide evidence of a maternal role of cAMP on embryogenesis. Dev Biol 121:432-444 
Brown MC, Ironton R (1977) Motoneuron sprouting induced by prolonged tetrodotoxin block of nerve action potential. Nature 265:459461.

Budnik V, Zhong Y, Wu C-F (1990) Morphological plasticity of motor axons in Drosophila mutants with altered excitability. J Neurosci 10: 3754-3768.

Buxbaum JD, Dudai Y (1989) In vivo protein phosphorylation in Drosophila mutants defective in learning and memory. Neurosci Lett 104:351-355.

Byers D, Davis RL, Kiger JA (1981) Defect in cyclic AMP phosphodiesterase due to the dunce mutation of learning in Drosophila melanogaster. Nature 289:79-81.

Chen CN, Denome S, Davis RL (1986) Molecular analysis of cDNA clones and the corresponding genomic coding sequences of the Drosophila dunce ${ }^{+}$gene, the structural gene for cAMP phosphodiesterase. Proc Natl Acad Sci USA 83:9313-9317.

Chetkovich DM, Sweatt JD (1990) Tetanic stimulation causes an APVsensitive increase in cAMP levels in rat hippocampal CA1 region. Soc Neurosci Abstr 16:65.1.

Cline HT (1991) Activity-dependent plasticity in the visual systems of frogs and fish. Trends Neurosci 14:104-111.

Constantine-Paton M, Cline HT, Debski E (1990) Patterned activity, synaptic convergence, and the NMDA receptor in developing visual pathways. Annu Rev Neurosci 13:129-154.

Corfas, G, Dudai Y (1991) The morphology of a sensory neuron in Drosophila is abnormal in memory mutants and changes during aging. Proc Natl Acad Sci USA 88:7252-7256.

Crossley CA (1978) The morphology and development of the Drosophila muscular system. In: The genetics and biology of Drosophila, Vol 2b (Ashburner M, Wright TRF, eds), pp 449-559. New York: Academic.

Devay P, Pinter M, Kiss I, Farago A, Friedrich P (1989) Protein kinase $\mathrm{C}$ in larval brain of wild-type and dunce memory-mutant Drosophila. J Neurogenet 5:119-126.

Drysdale R, Warmke J, Kreber R, Ganetzky B (1991) Molecular characterization of eag: a gene affecting potassium channels in Drosophila melanogaster. Genetics 127:497-505.

Dubinsky JM, Fischbach GDJ (1990) A role for cAMP in the development of functional neuromuscular transmission. J Neurobiol 21: $414-426$.

Dudai Y (1988) Neurogenetic dissection of learning and short-term memory in Drosophila. Annu Rev Neurosci 11:537-563.

Dudai Y, Zvi S (1984) Adenylate cyclase in the Drosophila memory mutant rutabaga is defective in its responsiveness to $\mathrm{Ca}^{2+}$. Neurosci Lett 47:119-124.

Dudai Y, Jan YN, Byers D, Quinn WG, Benzer S (1976) dunce, a mutant of Drosophila deficient in learning. Proc Natl Acad Sci USA 73:1684-1688.

Dudai Y, Uzzan A, Zvi S (1983) Abnormal activity of adenylate cyclase in the Drosophila memory mutant rutabaga. Neurosic Lett 42:207-212

Feany MB (1990) Rescue of the learning defect in dunce, a Drosophila learning mutant, by an allele of rutabaga, a second learning mutant. Proc Natl Acad Sci USA 87:2795-2799.

Forscher P, Kaczmarek LK, Buchanan J, Smith SJ (1987) Cyclic AMP induces changes in distribution and transport of organelles within growth cones of Aplysia bag cell neurons. J Neurosci 7:3600-3611.

Ganetzky B, Wu C-F (1983) Neurogenetic analysis of potassium currents in Drosophila: synergistic effects on neuromuscular transmission in double mutants. J Neurogenet 1:17-28.

Ganetzky B, Wu C-F (1986) Neurogenetics of membrane excitability in Drosophila. Annu Rev Genet 20:13-44.

Greenough WT, Bailey CH (1988) The anatomy of a memory: convergence of results across a diversity of tests. Trends Neurosci 11: 142-147.

Halpern ME, Anderson AMS, Johansen J, Keshishian H (1988) Octopamine immunoreactive nerve terminals are found on a single identified muscle fiber of the Drosophila larval body wall. Soc Neurosci Abstr 14:383.

Harris WA (1981) Neural activity and development. Annu Rev Physiol 43:689-710.

Haugland FN, Wu C-F (1990) A voltage-clamp analysis of gene dosage effects of the Shaker locus on larval muscle potassium currents in Drosophila. J Neurosci 10:1357-1371.

Hubel DH, Wiesel TN, LeVay S (1977) Plasicity of ocular dominance columns in monkey striate cortex. Philos Trans R Soc Lond [Biol] 278:377-409.

Jackson FR, Wilson SD, Strichartz GR, Hall LM (1984) Two types of mutants affecting voltage-sensitive sodium channels in Drosophila melanogaster. Nature 308:189-191.

Jan LY, Jan YN (1976) Properties of the larval neuromuscular junction in Drosophila melanogaster. J Physiol (Lond) 262:189-214.

Jan LY, Jan YN (1982) Antibodies to horseradish peroxidase as specific neuronal markers in Drosophila and grasshopper embryos. Proc Natl Acad Sci USA 72:2700-2704.

Jan YN, Jan LY, Dennis MJ (1977) Two mutations of synaptic transmission in Drosophila. Proc R Soc Lond [Biol] 198:87-108

Johansen J, Halpern ME, Johansen KM, Keshishian H (1989a) Stereotypic morphology of glutamatergic synapses on identified muscle cells of Drosophila larvae. J Neurosci 9:710-725.

Johansen J, Halpern ME, Keshishian H (1989b) Axonal guidance and the development of muscle fiber specific innervation in Drosophila embryos. J Neurosci 9:4318-4332.

Kandel ER, Schwartz JH (1982) Molecular biology of learning: modulation of transmitter release. Science 218:433-443.

Kater SB, Mills LR (1991) Regulation of growth cone behavior by calcium. J Neurosci 11:891-899.

Kater SB, Mattson MP, Cohan C, Connor J (1988) Calcium regulation of the neuronal growth cone. Trends Neurosci 11:315-321.

Krupinski J, Coussen F, Bakalyar HA, Tang W-J, Feinstein PG, Orth K, Slaughter C, Red RR, Gilman AG (1989) Adenylyl cyclase amino acid sequence: possible channel- or transporter-like structure. Science 244:1558-1568.

Lindsley DL, Grell EH (1968) Genetic variations of Drosophila melanogaster. Washington, DC: Carnegie Institution of Washington, Publication 627

Livingstone MS, Sziober PP, Quinn WG (1984) Loss of calcium/ calmodulin responsiveness in adenylate cyclase of rutabaga, a Drosophila learning mutant. Cell 37:205-215.

Lnenicka GA, Murphey RK (1989) The refinement of invertebrate synapses during development. J Neurobiol 20:339-355.

Lnenicka GA, Atwood HL, Marin L (1986) Morphological transformation of synaptic terminals of a phasic motoneuron by long-term tonic stimulation. J Neurosci 6:2252-2258.

Meyer RL (1982) Tetrodotoxin blocks the formation of ocular dominance columns in goldfish. Science 218:589-591.

Mohler JD (1977) Developmental genetics of the Drosophila egg. Identification of 59 sex-linked cistrons with maternal effects of embryonic development. Genetics 85:259-272.

Nairn AC, Hemmings HC Jr, Greengard P (1985) Protein kinases in the brain. Annu Rev Biochem 54:931-976.

Nazif F, Byrne JH, Cleary LJ (1991) cAMP induces a long-term morphological changes in sensory neurons of Aplysia. Brain Res 539:324 327.

Reh T, Constantine-Paton M (1985) Eye-specific segregation requires neural activity in three-eyed Rana pipiens. J Neurosci 5:1132-1143.

Rydel RE, Greene LA (1988) cAMP analogs promote survival and neurite outgrowth in cultures of rat sympathetic and sensory neurons independently of nerve growth factor. Proc Natl Acad Sci USA 85: 1257-1261.

Salkoff LB, Tanouye MA (1986) Genetics of ion channels. Physiol Rev 66:301-329.

Schmidt JT, Edwards DL (1983) Activity sharpens the map during the regeneration of the retinotectal projection in goldfish. Brain Res 269:29-39.

Sink H, Whitington PM (1991) Location and connectivity of abdominal motoneurons in the embryo and larva of Drosophila melanogaster. J Neurobiol 22: 298-311.

Tanouye MA, Ferrus A (1985) Action potentials in normal and Shaker mutant Drosophila. J Neurogenet 2:253-271.

Tully T (1984) Drosophila learning: behavior and biochemistry. Behav Genet 14:527-557.

Udin SB, Fawcett JW (1988) Formation of topographic maps. Annu Rev Neurosci 11:289-327.

Warmke J, Drysdale R, Ganetzky B (1991) The Drosophila eag locus encodes a novel potassium channel polypeptide. Science $252: 1560$ 1562.

Wu C-F, Ganetzky B, Jan LY, Jan Y-N, Benzer S (1978) A Drosophila mutant with a temperature-sensitive block in nerve conduction. Proc Natl Acad Sci USA 75:4047-4051. 
Wu C-F, Ganetzky B, Haugland FN, Liu A-X (1983) Potassium currents in Drosophila: different components affected by mutations of two genes. Science 220:1076-1078.

Zhong Y (1991) Activity-dependent mechanisms underlying synaptic plasticity in Drosophila memory mutants, pp 72-92. PhD thesis, The University of Iowa.
Zhong Y, Wu C-F (1991a) Altered synaptic plasticity in Drosophila memory mutant with altered cAMP cascade. Science 251:198-201. Zhong Y, Wu C-F (1991b) Alteration of four identified $\mathrm{K}^{+}$currents in Drosophila muscle by mutations in eag. Science 252:1562-1564. 